\title{
Malignant Brenner tumor of the ovary: Case series of one single institute
}

\author{
M.Bouhani ${ }^{1}$,M.Slimane ${ }^{1}$,S.Sghaier ${ }^{1}$, M.A.Bouida ${ }^{1}$,N.Boujelbene ${ }^{2}$,J.Ben Hassouna ${ }^{1}$,M.Hechiche \\ ${ }^{1}$,R.Chargui ${ }^{1}$,K.Rahal ${ }^{1}$ \\ ${ }^{1}$ Salah Azaiz Institute,Oncologic Surgery,Tunis,Tunisia; \\ 2 Salah Azaiz Institute,Anatomopathology,Tunis,Tunisia
}

\begin{abstract}
Objectives :
Malignant Brenner tumors (MBT) of the ovary are rare disease; representing $<1 \%$ of all ovarian cancers and $3-5 \%$ of Brenner tumors. They carry a poor prognosis. They generally affect women during the perimenopausal and postmenopausal periods. The standard treatment is surgery; however, the indication of adjuvant chemotherapy remains controversial. The aim of this study is to report our experience in the treatment of MBT of the ovary, to better characterize this disease.

Methods:

A retrospective case series involving 4 patients diagnosed with MBT of the ovary and treated between 2006 and 2014.

Results:

The mean age of our patients was 59.2 years. Three patients were in the menopause period. All women conducted surgery followed by adjuvant chemotherapy. Three patients presented a loco-regional recurrence that occurred respectively after 9 and 11 months in two patients. The treatment was based on chemotherapy. Two patients presented distant metastasis. The treatment combined chemotherapy and surgery. The patient's outcomes are resumed in the table 1
\end{abstract}

\section{Discussion:}

MBT of the ovary are uncommon accounting for $<1 \%$ of all ovarian cancers and $3-5 \%$ of Brenner tumors (1). They carry a poor prognosis (2). They don't present specific clinical manifestations or imaging features (3). Surgery is the cornerstone of the treatment of women with MBT (4). It consists of a hysterectomy, salpingooophorectomy, omentectomy, appendectomy with or without pelvic and para-aortic lymphadenectomy (5). The administration of adjuvant chemotherapy is not clearly demonstrated. Thus, the treatment of MBT seems to be a challenging topic; raising the importance of multidisciplinary teams in their management.

\section{Conclusion:}

The treatment approach of MBT of the ovary is not well established since its scarcity and poor prognosis. Thus, more case series and meta-analysis should be conducted.

Table1: Patients' outcomes:

\begin{tabular}{|c|c|c|c|c|}
\hline Case & 1 & 2 & 3 & 4 \\
\hline Stage & IIC & IIIC & IIIC & IC \\
\hline CT & $6 \mathrm{TC}$ & $6 \mathrm{TC}$ & $4 \mathrm{TC}+2 \mathrm{EC}$ & 6TC \\
\hline Second look & Yes & Yes & Yes & No \\
\hline $\begin{array}{l}\text { Recurrence / time to recurrence } \\
\text { (months) }\end{array}$ & Yes/ 9 & Yes/ 11 & Yes/ 11 & No \\
\hline Localization of recurrence & Pouch of Douglas & Prevesical peritoneum & Liver & - \\
\hline Treatment & - & CT & Surgery + CT & - \\
\hline evolution & progression & remission & relapse & - \\
\hline Treatment of metastasis & - & CT & - & Surgery + CT \\
\hline Follow up (months) & 14 & 39 & 64 & 59 \\
\hline
\end{tabular}

TC: Taxol-Carboplatin, EC: Endoxan-Carboplatin, CT: chemotherapy

Kurman, R. J., Carcangiu, M. L., Herrington, C. S., \& Young, R. H. (2014). WHO classification of tumours of female reproductive organs. Lyon: International Agency for Research on Cancer, 172. Balasa, R. W., Adcock, L. L., Prem, K. A., \& Dehner, L. P. (1977). The Brenner tumor: a clinicopathologic review. Obstetrics and gynecology, 50(1), 120-128.

Nasioudis, D. Sisti, G. Holcomb, K. Kanninen, T., \& Witkin, S. S. (2016). Malignant Brenner tumors of the ovary; a population-based analysis. Gynecologic oncology, 142(1), 44-49.

Bares, L. M. M., Asenjo, E. C., Muret, F. R. M., Moreno, M. G., Ortega, E. M., \& Casas, J. A. V. (2015). Malignant ovarian Brenner tumor. A case report evaluated with 18F-FDG PET/CT. Revista española de medicina nuclear e imagen molecular, 34(5), 337-338.

5. Verleye, L., Ottevanger, P. B., Van der Graaf, W., Reed, N. S., \& Vergote, I. (2009). EORTC-GCG process quality indicators for ovarian cancer surgery. European journal of cancer, 45(4), 517-526. 